\title{
Molecular identification of mango malformation pathogens in Egypt
}

\author{
Wafaa Mohamed Haggag $^{1 *}$, Mahmoud Hazza ${ }^{2}$, Mahmoud Saker ${ }^{3}$, Mohamed Abd El-Wahab ${ }^{1}$ \\ ${ }^{1}$ Department of Plant Pathology National Research Center, Cairo, Egypt; \\ ${ }^{2}$ Science Faculty, Botany Department, Banha University, Banha, Egypt; \\ ${ }^{3}$ Department of Plant Biotechnology, National Research Center, Cairo, Egypt.

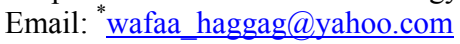

Received 16 February 2011; revised 21 May 2011; accepted 7 June 2011.

\begin{abstract}
Diagnostic tests by molecular biology is made for studying the relations among Fusarium species for linking production of proteins, degree of relationship and occurrence of malformation. Determination of proteins for isolates causing-disease by SDS-PAGE explained there's specific band for each fungus and there are common bands among some isolates of fungi. Since, band with MW 30 KDa represented only in $F$. proliferatum and F. oxysporum and $F$. subglutinans respectively. This band considered as specific band for these isolates, which released high pathogenisity effect. RAPD-PCR markers were used to discriminate variations between Fusarium isolates and causing disease. There is specific band for each fungus which act as molecular marker for each fungus and there are some bands common among some isolates of pathogenic fungi. The dendrogram shows there is degree of relationship between $F$. sterilihyphosum and $F$. proliferatum; between $F$. moniliforme and $F$. subglutinans; between $F$. oxysporum and $F$. chlamydospore; the degree of relationship among $F$. subglutinans, F. proliferatum and F. sterilihyphosum and degree of relationship among $F$. moniliforme, $F$. sterilihyphosum, F. proliferatum and F. subglutinans
\end{abstract}

Keywords: Fusarium Spp.; Mango Malformation

\section{INTRODUCTION}

Mango (Mangifera indica L.) is the most important fruit grown in tropical and subtropical region of the world. Mango is the most important fruit crop in Egypt. Mango malformation is one of the most destructive mango diseases [1]. Losses due to malformation have not been accurately assessed because yield loss is not a linear function of disease severity [2]. A number of Fusarium species has been reported to be associated with the mal- formation disease of mango [3]. Some Fusarium species especially those insection Liseola and their allied, identification process based solely on morphological characteristics are not always convincing and still incomplete and inconclusive. Therefore, molecular characterization can be used as additional criteria for species characterization and identification. Genetic diversity was examined among $74 \mathrm{~F}$. subglutinans - like isolates from malformed mango in Brazil, Egypt, Florida (USA), India, Israel and South Africa. With nitrate-non-utilizing (nit) auxotrophic mutants, seven vegetative compatibility groups (VCGs) were identified. Three of the VCGs were found in a single country, and VCG diversity was greatest in Egypt and the USA where, respectively, four and three different VCGs were found. RAPD profiles generated with arbitrary decamer primers were variable among isolates in different VCGs, but were generally uniform for isolates within a VCG. In PCR assays, a 20-mer primer pair that was developed previously to identify F. subglutinans from maize (mating population (MP-E) of the Gibberella fujikuroi complex) also amplified a specific $448 \mathrm{bp}$ fragment for isolates of $F$. sacchari from sugarcane (MP-B) and what was probably $F$. circinatum (pine, MP-H). With the exception of three isolates from Brazil, it did not amplify the fragment from $F$. subglutinanslike isolates from mango. A second pair of 20-mer primers was developed from a unique fragment in the RAPD assays. It amplified a specific 608 bp fragment for 51 of 54 isolates from mango (all but the three Brazilian isolates). It also amplified a smaller, $550 \mathrm{bp}$ fragment from isolates of F. nygamai (MP-G), but did not amplify DNA of isolates of any other toxin of Fusarium that was tested [4].

A wild-type isolate of $F$. subglutinans causing mango malformation disease was transformed with the GUS (B glucuronidase) reporter and hygromycin resistance genes. Five stable transformants were isolated containing varying copy numbers at different integration sites. Specific 
GUS activity was quantified for the transformants, whereas no activity was recorded for the wildtype isolate. The transformants and the wild-type isolate were inoculated into healthy mango floral and vegetative buds. Typical symptoms of misshapen shoots with short internodes, stub by leaves, and bunchy, malformed inflorescences were observed 6 to 8 weeks following inoculation. The presence of GUS - stained mycelium of the pathogen viewed microscopically within infected plant organs provided unequivocal evidence that $F$. subglutinans is indeed a causal agent of mango malformation disease [5].

According to PCR - specific primer amplification, the pathogen was detected in $97 \%$ of seedling apical meristems, declining gradually to $5 \%$ colonization in roots. It was concluded that inoculum of the pathogen originates from infected panicles and affects seedlings from the meristem, with infections descending to lower stem sections and roots. Minor infections of roots may occur from inoculum originating from infected panicles, but the pathogen is not seed borne [6]. In order to characterize molecularly the etiological agent of mango floral and vegetative malformation in Brazil AFLPs, sequence analysis and assays were used. The AFLP patterns of the majority of isolates collected in Brazil were different from Fusarium mangiferae and Fusarium sterilihyphosum, two previously described Fusarium species associated with mango malformation. The cluster analysis of AFLP data using Dice coefficient produced a network where Fusarium spp. from Brazil were in one group apart from two other groups represented by isolates of F. sterilihyphosum from Brazil and South Africa, and by isolates of F. mangiferae from Egypt, India, South Africa and USA, respectively. Fusarium spp. from Brazil was compared with 24 species of the Gibberella fujikuroi complex (GFC) using AFLP data and showed to be a distinctive species. Sequence analyses of portions of amp; \#946tubulin and EF-1amp and \#945; were used to elucidate the phylogenetic relationships between Fusarium spp. from Brazil and the species of the GFC. Maximum parsimony analyses grouped this Fusarium spp. in the American clade, but within a distinct subgroup which indicates a different species close related to F. sterilihyphosum. These species are not easily separated when only morphological characters are used, but can be distinguished through AFLP patterns, fertility and sequence analyses [3].

Thus, objective of the present study is to molecular characterization of Fusarium spp. to identify the mango malformation pathogens in Egypt

\section{MATERIALS AND METHODS}

Seven Fusarium specie i.e. F. oxysporium, F. proliferatum, $F$. subglutinans, $F$. sterilihyphosium, $F$. monilifrme and $F$. Avenaceum isolated from malformed mango blossom tissue were tested for their ability to cause malformation. Mango seedling cv. Sedekia (two years old) was inoculated with $10^{5}$ colony forming units of Fusarium spp. as inoculated soil. Four replications of six seedlings each were evaluated. Sterilized water was used as a control. Transplanted seedlings were monitored for development of malformation. At the end of the experiment (120 days), all surviving seedlings were examined for apical disease symptoms. Data were recorded on symptoms manifestation as diseases incidence and severity. The isolates were cultured on PDA overlaid with four pieces of sterile-osmosis membrane for seven days under the standard growth conditions. Approximately $100 \mathrm{mg}$ of mycelium were used for protein and DNA extractions

\subsection{SDS-PAGE Analysis of Total Protein}

Protein extraction: protein was extracted from Fusarium isolates according to Reuveni, et al. [7] with some modified. Harvest and rapidly wash the cell once with $0.1 \mathrm{M}$ $\mathrm{NaCl}$, then resuspended the cell pellet with lyses solution, which included of $100 \mathrm{mM}$ Tris-HCL (PH 8.0), 5\% (vol/vol) glycerol, 2 mM EDTA, 2\% SDS, 5\% sucrose. Then place the tube on ice for $3 \mathrm{~min}$. and rapidly in water bath at $100^{\circ} \mathrm{C}$ for $3 \mathrm{~min}$. repeated that tree times. Examine the suspension by microscopy to accretion that breakage has occurred. If not, quickly freeze and boil the sample again. Centrifuge at high speed under cooling. Remove the supernatant to another tube.

\subsubsection{Gel Preparation}

Sodium dodocylsulphate polyacrylamide gel electrophoresis (SDS-PAGE) was performed using 12.5\% acrylamide and $8 \%$ bis acrylamide running gel $(65 \mathrm{~mm} \times 70$ $\mathrm{mm})$ consisting of $0.375 \mathrm{M}$ Tris- $\mathrm{HCl}(\mathrm{pH} 8.8)$ and $0.1 \%$ SDS. Stacking gels $(10 \mathrm{~mm})$ were made using $4.5 \%$ acrylamide containing $8 \%$ bis-acrylamide in $0.125 \mathrm{M}$ Tris- $\mathrm{HCl}(\mathrm{pH}$ 6.8) and $0.1 \%$ SDS. The electrophoresis buffer contained $0.025 \mathrm{M}$ Tris- $\mathrm{HCl}, 0.19$ glycine and $0.1 \%$ SDS. The samples were homogenized in $0.12 \mathrm{M}$ Tris-HCl (pH 6.8), 0.4\% SDS, 10\% $\beta$-merkaptoethanol, $0.02 \%$ bromophenol blue, and $20 \%$ glycerol. The samples were then heated for $3 \mathrm{~min}$. in a boiling water bath before centrifugation. The gels were run under cooling at $90 \mathrm{~V}$ for the first $15 \mathrm{~min}$, then $120 \mathrm{~V}$ for the next $0.5 \mathrm{~h}$. and finally $150 \mathrm{~V}$ for the remaining $1.5 \mathrm{~h}$.

\subsubsection{Sample Loading}

A volume of $15 \mu \mathrm{l}$ protein sample was applied to each well by micropipette. Control wells were loaded with standard protein marker.

\subsubsection{Electrophoresis Conditions}

Four liters of running buffer were poured into the running tank to be pre-cooled $\left(4^{\circ} \mathrm{C}\right)$. Eight hundred $\mathrm{ml}$ of running buffer was added in the upper tank just before 
running so that the gels were completely covered. The electrodes were connected to power supply and adjust at $100 \mathrm{~V}$ until the bromophenol blue dye entered the resolving gel, and then increased to $250 \mathrm{~V}$ until the bromophenol blue dye reached the bottom of the resolving gel. The small triangle of one corner gel was marked so the orientation is not during staining.

\subsubsection{Gel Staining and Destaining}

After the completed of the run, gel was placed in staining solution consisting of (1 g Coomassie Brillint blueR-250; $455 \mathrm{ml}$ Methanol; $90 \mathrm{ml}$ Acetic acid glacial and up to $1 \mathrm{~L}$ with D.D.W.), and detained with $200 \mathrm{ml} \mathrm{de-}$ staining solution and agitated gently on shaker. The distaining solution was changed several times until the gel background was clear.

\subsubsection{Gel Analysis}

Gels were photographed using a Bio-Rad gel documentation system. Data analysis was obtained by Bio-Rad Quantity one software version 4.0.3.

\subsubsection{Native Gel Preparation}

The methods described by Stegemann et al. [8] 30\% Acrylamide: $29.2 \mathrm{~g}$ Acrylamide, $0.8 \mathrm{~g} \mathrm{~N}, \mathrm{~N}-m e t h y l e n e$ bisacrylamide were dissolved $100 \mathrm{ml} \mathrm{H}_{2} \mathrm{O}$ (dd.). $2 \%$ ammonium persulphate: $0.25 \mathrm{~g}$ ammonium persulphate was dissolved with $10 \mathrm{ml} \mathrm{H}_{2} \mathrm{O}$ (dd.). This stock must be prepared immediately before use. Buffer solution: this Borate buffer ( $\mathrm{pH}$ 8.9) was used for Isozymes analysis. The stock solution was composed of $605 \mathrm{~g}$ tris and $46 \mathrm{~g}$ boric acid dissolved in $5000 \mathrm{ml} \mathrm{H}_{2} \mathrm{O}$ (dd.). Electrode buffer: $(0.125 \mathrm{M}, \mathrm{pH} 8.9)$ was prepared by dilution of $300 \mathrm{ml}$ of the stock solution with $2100 \mathrm{ml} \mathrm{H}_{2} \mathrm{O}$ (dd.).

\subsubsection{Gel Preparation}

$35 \mathrm{ml}$ of $30 \%$ Acrylamide was added with $70 \mathrm{ml}(0.125$ $\mathrm{M}, \mathrm{pH} 8.5$ ) dilute buffer to get $8 \%$ Acrylamide, $33 \mathrm{mg}$ sodium sulphate (dissolve completely) $66 \mathrm{ml}$ TEMED (teteramethylenediamine) and $2.5 \mathrm{ml}$ ammonium persulphate the gel solution was quickly poured immediately and 15 well combs were used, then gels were left for about 30 minutes for polymerization

\subsection{Molecular Genetic Study (RAPD-PCR) A-DNA Extraction}

DNA isolation was performed using the CTAB method of Doyle and Doyle [9]. $0.5 \mathrm{~g}$ fresh sample from Sesamum indicum was ground to powder in liquid nitrogen with a prechilled pestle and mortar, suspended in $1 \mathrm{ml}$ preheated CTAB buffer, and incubated at $65^{\circ} \mathrm{C}$ for $1 \mathrm{~h}$ with occasional shaking then centrifuge for $10 \mathrm{~min}$ at 1000 rpm. Transfer the supernatant to a new tube by wide pore, add $0.5 \mathrm{ml}$ of (chloroform: isoamylol) 24:1 then centrifuge for 15 minutes at $14,000 \mathrm{rpm}$ and the aqueous layer was transferred to a new sterilized tube (avoid protein surface). The ice cold isopropanol was added to precipitate the nucleic acid (RNA, DNA) then Incubate at $-20^{\circ} \mathrm{C}$ overnight and centrifugation was happened at $14,000 \mathrm{rpm}$ for 20 minutes. The supernatant was discard and the pellet was washed carefully twice with cold $70 \%$ ethanol, dried at room temperature and resuspend in 100 $\mu l$ of sterile deionized distilled water. DNA concentration was determined by electrophoresis of $5 \mu \mathrm{l}$ of DNA with $2 \mu \mathrm{l}$ of loading buffer and run at $100 \mathrm{~V}$ for approximately 30 minutes.

\subsection{B-RAPD Analysis}

RAPD was performed as described by Williams et al. [10] with minor modifications. Briefly, PCR amplification was performed in $25 \mu \mathrm{l}$ reaction mix (Tables 1-3) containing $20.40 \mathrm{ng}$ genomic DNA, 0.5 unit Taq polymerase (Sigma), $0.2 \mathrm{mM}$ each of dATP, dCTP, dGTP and dTTP, 5 Pico mole random primer and appropriate amplification buffer. The reaction was assembled on ice, overlaid with a drop of mineral oil. Amplification was performed for 45 cycles (Table 2) using Biometera Uno thermal cycler, as follows: One cycle at $95^{\circ} \mathrm{C}$ for $3 \mathrm{~min}-$ utes and then 44 cycles at $92^{\circ} \mathrm{C}$ for 2 minutes, $37^{\circ} \mathrm{C}$ for 1 minute and $72^{\circ} \mathrm{C}$ for 2 minutes (for denaturation, annealing and extension, respectively). Reaction was finally incubated at $72^{\circ} \mathrm{C}$ for 10 minutes and further incubated on $4^{\circ} \mathrm{C}$.Five primers were used for RAPD analysis based on their ability to amplify Amaransis genome and producing reproducible amplification patterns (Table 4).

\subsection{C-Agarose Electrophoresis}

The amplification products were analyzed by electrophoresis in $2 \%$ agarose in TAE buffer stained with 0.2 $\mu \mathrm{g} / \mathrm{ml}$ ethidium bromide and photographed under UV light. The buffer was added to the agarose then heated in a microwave tell melting, cooling to $60^{\circ} \mathrm{C}$ then the ethia microwave tell melting, cooling to $60^{\circ} \mathrm{C}$ then the ethidium bromide was added. Sample was prepared by using

Table 1. Components of RAPD-PCR mixture.

\begin{tabular}{ccc}
\hline Reagent & Concentration & Volume \\
\hline d NTP $_{\mathrm{S}}$ & $0.2 \mathrm{mM}$ & $2.5 \mu \mathrm{l}$ \\
PCR buffer & $10 \times$ & $5 \mu \mathrm{l}$ \\
Ampli Taq polymerase (RTS Taq DNA \\
polymerase). & 2 Units & $0.25 \mu \mathrm{l}$ \\
$\mathrm{MgCl}_{2}$ & & $1.5 \mu \mathrm{l}$ \\
Primer $_{\text {Distilled sterile water }}$ & $5 \mathrm{p} \mathrm{mole}$ & $3 \mu \mathrm{l}$ \\
Total genomic DNA & - & $9.75 \mu \mathrm{l}$ \\
Total volume & $20.40 \mathrm{ng}$ & $3 \mu \mathrm{l}$ \\
\hline
\end{tabular}


Table 2. PCR program (temperature profile).

\begin{tabular}{ccccc}
\hline Order & Action & Temperature & Duration & No. of cycles \\
\hline $\mathbf{1}$ & 1stDenaturation & $95^{\circ} \mathrm{C}$ & 3 minutes & 1 cycle \\
$\mathbf{2}$ & Denaturation & $92^{\circ} \mathrm{C}$ & 2 minutes & \\
$\mathbf{3}$ & Annealing & $37^{\circ} \mathrm{C}$ & 1 minutes & 44 cycles \\
$\mathbf{4}$ & Extension & $72^{\circ} \mathrm{C}$ & 2 minutes & \\
$\mathbf{5}$ & Last extension & $72^{\circ} \mathrm{C}$ & 10 minutes & 1 cycle \\
$\mathbf{6}$ & Incubation & $4^{\circ} \mathrm{C}$ & & \\
\hline
\end{tabular}

Table 3. Composition of stocks.

\begin{tabular}{|c|c|}
\hline Stock & Composition \\
\hline СТАВ & $\begin{array}{c}\text { 1.4 M Nacl, } 0.2 \% \beta \text {-mercaptoethanol, } 100 \mathrm{mM} \\
\text { Tris- } \mathrm{HCl} \text { and } 20 \mathrm{mM} \text { EDTA }\end{array}$ \\
\hline $\begin{array}{l}50 \times \text { Tris-Acetate } \\
\text { Buffer }\end{array}$ & $\begin{array}{c}242 \mathrm{~g} \text { Tris-base, } 57.1 \mathrm{ml} \text { Glacial acetic acid and } \\
100 \mathrm{ml} \text { EDTA }(0.5 \mathrm{M}, \mathrm{pH} 8.0)\end{array}$ \\
\hline Loading buffer & $\begin{array}{l}0.25 \mathrm{~g} \text { bromophenol blue and } 100 \mathrm{ml} \text { Glycerol } \\
(30 \%)\end{array}$ \\
\hline Ethidium bromide & $0.2 \mu \mathrm{g} / \mathrm{ml}$ ethidium \\
\hline
\end{tabular}

Table 4. Name and sequences of the selected random primers used in RAPD-PCR analysis and make amplification.

\begin{tabular}{ccc}
\hline \multicolumn{2}{c}{ Primer code } & Nucleotide sequences $\mathbf{( 5 - 3 )}$ \\
\hline $\mathbf{1 -}$ & A1 & CAGGCCCTTC \\
2- & A3 & AGTCAGCCAC \\
3- & A4 & AATCGGGCTG \\
4- & B1 & GTTTCGCTCC \\
$\mathbf{5 -}$ & B4 & GGACTGGAGT \\
$\mathbf{6 -}$ & G2 & GGCACTGAGG \\
7- & Z1 & TCTGTGCCAC \\
$\mathbf{8 -}$ & G3 & GAGCCCTCCA \\
$\mathbf{9 -}$ & Z3 & CAGCACCGCA \\
$\mathbf{1 0}-$ & A2 & TGCCGAGCTG \\
\hline
\end{tabular}

Name of primers that did not make amplification G2, B4, B1, A1, A4.

$10 \mu 1$ PCR-product and $2 \mu 1$ loading buffer. One marker was used, $100 \mathrm{bp}$ DNA ladder (Axygen).

\section{RESULTS AND DISCUSSION}

Seven fungi viz. F. subglutinans, F. oxyspoum, F. sterilihyphosum, F. proliferatum, F. moniliforme, F.avena and $F$. chlamydspore isolated from mango malformed tissue were tested using susceptible Sadekia cultivar as inoculated soil (Table 5). Data pertaining to artificial inoculations revealed that effort to produce disease by soil inoculation with spores suspension. Four Fusarium subglutinans proved to be the dominant fungus with $100 \%$ sample's infection in inoculated soil. Fungi $F$. oxysporum, F. sterilihyphosum and F. proliferatum showed moderate infection in induced typical malformation symptoms in inoculated mango seedling and were reisolated . Other Fusarium spp. give grown and root rots symptoms.

\subsection{Molecular Characterization of Fusarium Isolates}

Molecular characterization of the eight Fusarium isolates was carried out using sodium dodocyle sulphate
Table 5. Comparative virulence of selected Fusarium isolates on inoculated mango cv. Sedekia seedlings.

\begin{tabular}{ccc}
\hline \multirow{2}{*}{ Tested isolates } & \multicolumn{2}{c}{ Infested soil with spore suspension } \\
\cline { 2 - 3 } Disease incidence \% & Disease severity \\
\hline F. subglutinans & $100.0 \mathrm{a}$ & $4.0 \mathrm{a}$ \\
F. oxyspoum & $50.0 \mathrm{~b}$ & $1.3 \mathrm{c}$ \\
F. sterilihyphosum & $50.0 \mathrm{~b}$ & $2.3 \mathrm{~b}$ \\
F. solani & $0.0 \mathrm{c}$ & $0.0 \mathrm{~d}$ \\
F. avenaceum & & \\
F. chlamydspore & $0.0 \mathrm{c}$ & $0.0 \mathrm{~d}$ \\
\hline
\end{tabular}

\begin{tabular}{|llllllllll}
\hline & 1 & 2 & 3 & 4 & 5 & 6 & 7 & 8 \\
\hline
\end{tabular}

Figure 1. SDS-PAGE of total proteins extracted from eight Fusarium isolates $(1=F$. proliferatum, $2=F$. oxysporum, $3=$ $F$. solani, $4=F$. chlamydsporium, $5=F$. moniliforme, $6=F$. sterilihyphosum, $7=F$. avenaceum, $8=F$. subglutinans, $\mathrm{M}$ refers to protein stander).

polyacrylamide gel electrophoresis (SDS-PAGE) analysis.

\subsection{SDS-PAGE Analysis of Total Protein}

Total proteins were separated by SDS-PAGE. Figure 1 shows the electrophoretic pattern of Fusarium isolates. The maximum number of the bands was twenty-six, as shown in Table 6. The molecular weight of the bands obtained with SDS-PAGE ranged from 14 to $215 \mathrm{KDa}$. Most band are considered as common band exept bands with molecular weight (MW) 215 and $210 \mathrm{KDa}$ which represented only in three isolates, F. chlamydsporium, $F$. moniliforme and $F$. sterilihyphosum respectively. As they appeared only in two isolates F.proliferatum and $F$. oxysporum respectively bands with MW 100, 88, 50, 30 and 20. These bands are not found in the rest of isolates and considered as potential marker associated with theses isolates and their pathogenisty. While band with MW $30 \mathrm{KDa}$ represented only in $F$. proliferatum, $F$. oxysporum and F. subglutinans respectively. This band considered as specific band for these isolates, which released high pathogenisity effect. 
Table 6. SDS-PAGE protein banding pattern extracted from eight Fusarium isolates.

\begin{tabular}{|c|c|c|c|c|c|c|c|c|c|}
\hline No. & MW & 1 & 2 & 3 & 4 & 5 & 6 & 7 & 8 \\
\hline 1 & 215 & - & - & - & + & + & + & - & - \\
\hline 2 & 210 & - & - & - & + & + & + & - & - \\
\hline 3 & 205 & + & + & + & + & + & + & + & + \\
\hline 4 & 200 & - & + & + & - & - & - & - & - \\
\hline 5 & 116 & + & + & + & + & + & + & + & + \\
\hline 6 & 115 & - & - & + & + & + & + & + & + \\
\hline 7 & 110 & + & + & + & - & - & - & - & - \\
\hline 8 & 100 & + & + & - & - & - & - & - & - \\
\hline 9 & 97 & + & + & + & + & + & + & + & + \\
\hline 10 & 88 & + & + & - & - & - & - & - & - \\
\hline 11 & 80 & + & + & + & + & + & + & + & + \\
\hline 12 & 75 & + & + & + & + & + & + & + & + \\
\hline 13 & 66 & + & + & + & + & + & + & + & + \\
\hline 14 & 60 & + & + & - & + & + & + & + & + \\
\hline 15 & 55 & + & + & + & + & + & + & + & + \\
\hline 16 & 50 & + & + & - & - & - & - & - & - \\
\hline 17 & 45 & - & - & + & + & + & + & + & + \\
\hline 18 & 40 & - & - & + & + & + & + & + & + \\
\hline 19 & 35 & + & + & - & - & - & - & - & + \\
\hline 20 & 30 & + & + & - & - & - & - & - & - \\
\hline 21 & 29 & + & + & + & + & + & + & + & + \\
\hline 22 & 26 & + & + & + & + & + & + & + & + \\
\hline 23 & 25 & - & - & + & + & + & + & + & + \\
\hline 24 & 20 & + & + & - & - & - & - & - & - \\
\hline 25 & 16 & - & - & - & + & - & + & - & - \\
\hline 26 & 14 & + & + & + & + & + & + & + & + \\
\hline
\end{tabular}

$\mathrm{MW}=$ Molecular weight; $+=$ Presence of band.; $-=$ Absence of band From $1=F$. proliferatum, $2=F$. oxysporum, $3=F$. solani, $4=F$. chlamydsporium, $5=F$. moniliforme, $6=F$. sterilihyphosum, $7=F$. avenaceum, $8=F$. subglutinans, respectively.

\subsection{Molecular Genetic Study (RAPD-PCR)}

In the present study RAPD-PCR markers were used to discriminate variations between Fusarium isolates. RAPD would be the markers of choice, since it offers the advantages of being technically undemanding, use no radioactivity or polyacrylamide. Furthermore, RAPD-markers tend to reside in regions with many repeated sequences and their fore in non coding regions, which are more susceptible to mutations. Consequently, they usually reveal more polymorphism compared with isozymes or RFLPs, which are mostly representative of conserved genome regions [10]

\subsection{RAPD-PCR Using G3 Primer}

The results of RAPD analysis using primer G3 are illustrated in Figure 2 and Table 7 for all Fusarium isolates. The maximum number of bands by this primer was nine. The molecular weight of the PCR products generated by this primer ranged from 90 to 950 base paires (bp). Only band with MW 600 bp could be considered as common band. Bands with MW 950, 870 and 350 bp are considered as specific bands or positive markers of Fusarium isolates i.e. F. oxysporum, F.subglutinans. While the

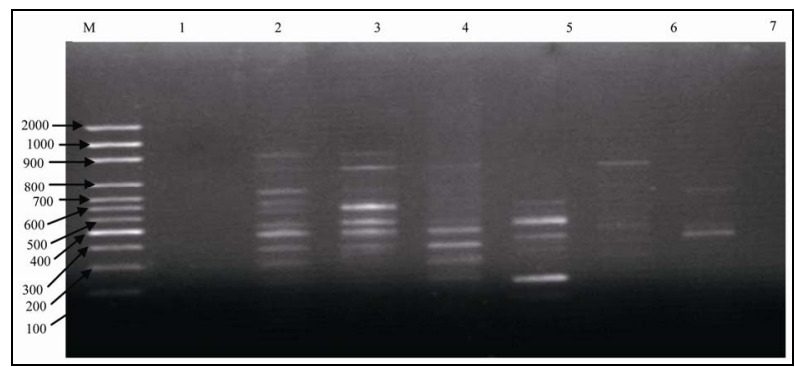

Figure 2. DNA polymorphesim based on RAPD-PCR analysis of the seven Fusarium isolates against the primer G3 $(1=F$. proliferatum, $2=F$. oxysporum, $3=F$. subglutinans, $4=F$. chlamydsporium, $5=F$. moniliforme, $6=F$. sterilihyphosum, 7 $=F$. avenaceum, $\mathrm{M}$ refers to ladder DNA stander marker).

Table 7. RAPD profiles of the Fusarium isolates using primer G3.

\begin{tabular}{ccccccccc}
\hline No. & MW & $\mathbf{1}$ & $\mathbf{2}$ & $\mathbf{3}$ & $\mathbf{4}$ & $\mathbf{5}$ & $\mathbf{6}$ & $\mathbf{7}$ \\
\hline 1 & 950 & - & + & + & - & - & - & - \\
2 & 870 & - & + & + & + & - & - & - \\
3 & 750 & - & + & + & + & - & - & - \\
4 & 600 & - & + & + & + & + & + & + \\
5 & 550 & - & + & + & - & + & - & - \\
6 & 350 & - & + & + & - & - & - & - \\
7 & 250 & - & + & + & - & + & + & + \\
8 & 150 & - & + & + & + & + & - & - \\
9 & 90 & - & - & - & - & + & - & - \\
\hline
\end{tabular}

MW = Molecular weight; $+=$ Presence of band $;-=$ Absence of band. From 1 to $7=F$. proliferatum, $F$. oxysporum, $F$. subglutinans, $F$. chlamydsporium, F. moniliforme, $F$. sterilihyphosum, F. avenaceum respectively.

band with MW 90 bp could be considered as specific marker for $F$. moniliforme. The disappearance of the band with MW 250 bp could considered as negative marker to F. chlamydsporium.

\subsection{RAPD-PCR Using Z3 Primer}

The results of RAPD analysis using primer Z3 are illustrated in Figure $\mathbf{3}$ and Table $\mathbf{8}$ for all Fusarium isolates. The maximum number of bands by this primer was eight. The molecular weight of the PCR products generated by this primer ranged from 100 to 800 base paires (bp). Only band with MW 500 bp could be considered as common band. Bands with MW 800 and 700 bp are considered as specific bands or positive markers of Fusarium isolates i.e. $F$. oxysporum and $F$. subglutinans. While the band with MW 100 bp could be considered as specific marker for $F$. proliferatum and $F$. moniliforme. The disappearance of the band with MW 200 and $300 \mathrm{bp}$ could consider as negative marker to $F$. avenaceum.

\subsection{RAPD-PCR Using A2 Primer}

The results of RAPD analysis using primer A2 are illus- 


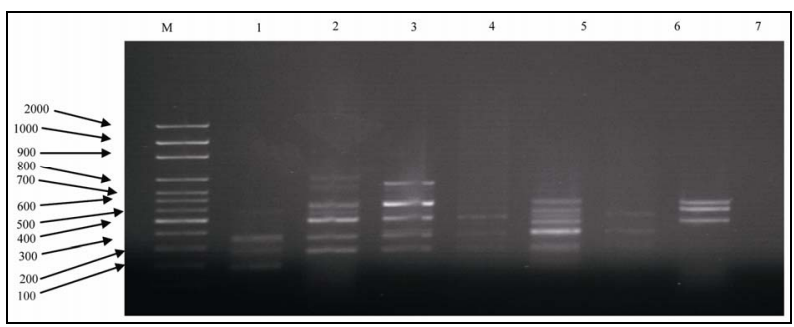

Figure 3. DNA polymorphesim based on RAPD-PCR analysis of the seven Fusarium isolates against the primer Z3 $(1=F$. proliferatum, $2=F$. oxysporum, $3=F$. subglutinans, $4=F$. chlamydsporium, $5=F$. moniliforme, $6=F$. sterilihyphosum, 7 $=F$. avenaceum, $\mathrm{M}$ refers to ladder DNA stander marker).

Table 8. RAPD profiles of the Fusarium isolates using primer Z3.

\begin{tabular}{ccccccccc}
\hline No. & MW & $\mathbf{1}$ & $\mathbf{2}$ & $\mathbf{3}$ & $\mathbf{4}$ & $\mathbf{5}$ & $\mathbf{6}$ & $\mathbf{7}$ \\
\hline 1 & 800 & - & + & + & - & - & - & - \\
2 & 700 & - & + & + & - & - & - & - \\
3 & 600 & - & + & + & - & + & - & + \\
4 & 500 & + & + & + & + & + & + & + \\
5 & 400 & - & + & + & + & + & + & + \\
6 & 300 & + & + & + & + & + & + & - \\
7 & 200 & + & + & + & + & + & + & - \\
$\mathbf{8}$ & 100 & + & - & - & - & + & - & - \\
\hline
\end{tabular}

MW = Molecular weight; $+=$ Presence of band.; $-=$ Absence of band. From 1 to $7=F$. proliferatum, $2=F$. oxysporum, $3=F$. subglutinans, $4=F$. chlamydsporium, $5=$ F.moniliforme, $6=$ F.sterilihyphosum, $7=F$. avenaceum, respectively.

trated in Figure 4 and Table 9 for all Fusarium isolates. The maximum number of bands by this primer was nine. The molecular weight of three PCR products generated by this primer ranged from 100 to 900 base paires (bp). Band with MW 800 bp is considered as specific bands or positive marker of $F$. subglutinans. While the band with MW 600 and $400 \mathrm{bp}$ could be considered as specific markers for F. oxysporum. Bands with MW 700 and 200 bp are considered as specific bands or positive marker of $F$. moniliforme and $F$. proliferatum. The disappearance of the band with MW 250 bp could considered as negative marker to F. chlamydsporium.

\subsection{The Relationship between Fusarium Isolates}

The dendrogram shows in Figure 5, there is degree of relationship between $F$. sterilihyphosum and $F$. proliferatum; between $F$. moniliforme and $F$. subglutinans; between $F$. oxysporum and $F$. chlamydospore; the degree of relationship among, $F$. proliferatum and $F$. sterilihyphosum and degree of relationship among F. moniliforme, F. sterilihyphosum, F. proliferatum and F. subglutinans. These species are not easily separated when only

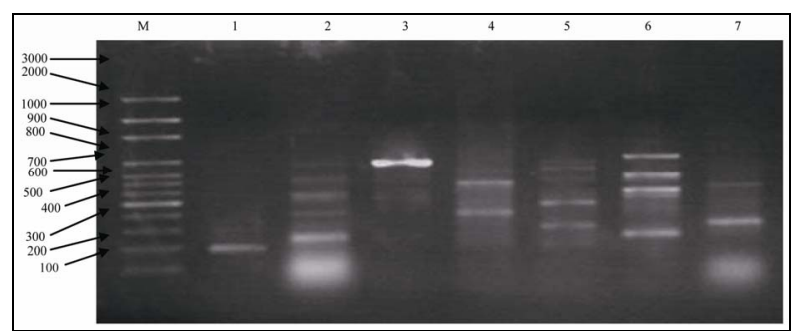

Figure 4. DNA polymorphesim based on RAPD-PCR analysis of the seven Fusarium isolates against the primer A2 $(1=F$. proliferatum, $2=F$. oxysporum, $3=F$. subglutinans, $4=F$. chlamydsporium, $5=F$. moniliforme, $6=F$. sterilihyphosum, 7 $=F$. avenaceum, $\mathrm{M}$ refers to ladder DNA stander marker).

Table 9. RAPD profiles of the Fusarium isolates using primer A2.

\begin{tabular}{ccccccccc}
\hline No. & MW & $\mathbf{1}$ & $\mathbf{2}$ & $\mathbf{3}$ & $\mathbf{4}$ & $\mathbf{5}$ & $\mathbf{6}$ & $\mathbf{7}$ \\
\hline 1 & 900 & - & - & - & - & - & + & - \\
2 & 800 & - & - & + & - & - & - & - \\
3 & 700 & + & - & - & - & + & - & - \\
4 & 600 & - & + & - & - & - & - & - \\
5 & 500 & - & + & - & + & - & - & + \\
6 & 400 & - & + & - & - & - & - & - \\
7 & 300 & + & + & - & - & - & + & - \\
8 & 200 & + & - & - & - & + & - & - \\
9 & 100 & - & + & - & - & - & - & +
\end{tabular}

MW = Molecular weight; $+=$ Presence of band.; $-=$ Absence of band. From 1 to $7=F$. proliferatum, $2=F$. oxysporum, $3=F$. subglutinans, $4=F$. chlamydsporium, $5=F$. moniliforme, $6=F$. sterilihyphosum, $7=F$. avenaceum, respectively.

morphological characters are used. Therefore, molecular characterization can be used as additional criteria for species characterization and identification. In order to identify and characterize molecularly the etiological agent of mango floral and vegetative malformation, SDSPAGE of total proteins and RAPD-PCR assays were used. The RAPD-PCR technique has been used successfully by the Tree Pathology. SDS-PAGE of total proteins of portions and RAPD-PCR were used to elucidate the phylogenetic relationships between Fusarium species $[4,11,12]$. In many ways, molecular approaches are more easier and can provide results that are less ambiguous and the most important criteria is the same observations can be made between different researchers, as compared to morphological approach.

RAPD banding patterns showed similarity and variations between the seven Fusarium species isolated from mango infected plants. Since, relationship between $F$. sterilihyphosum and $F$. proliferatum; between $F$. moniliforme and F. subglutinans; between F.oxysporum and $F$. chlamydospore; the degree of relationship among, $F$. 
Cluster Tree

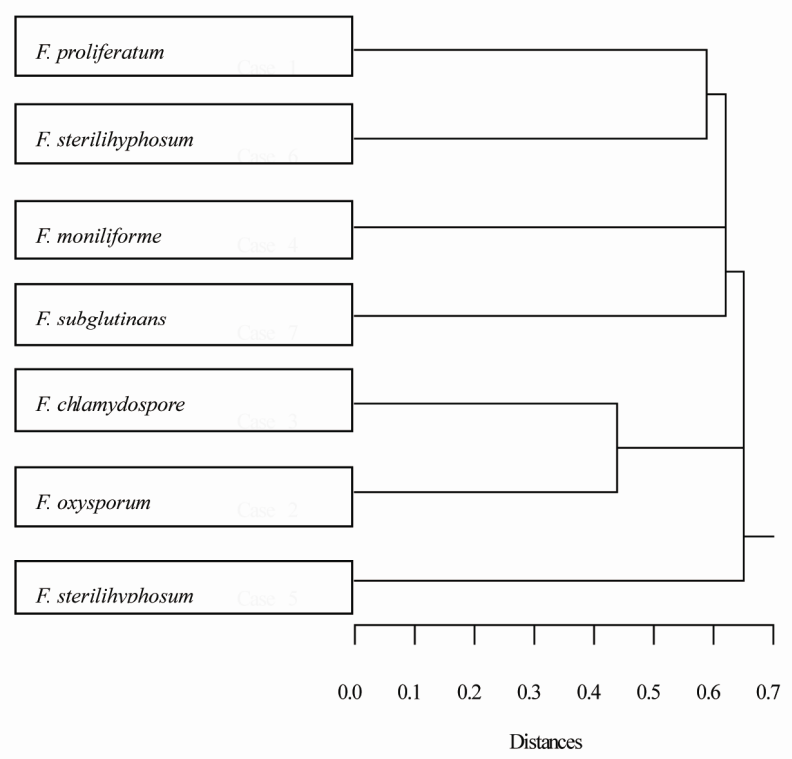

Figure 5. The dendrogram that release the relation ship between the seven Fusarium isolates.

proliferatum and $F$. sterilihyphosum and degree of relationship among F. moniliforme, $F$. sterilihyphosum, F. proliferatum and $F$. subglutinans were found. In addition, these bands are not found in the rest of isolates and considered as potential marker associated with theses isolates and their pathogenisty.

Results of RAPD analysis can be used to differentiate isolates of pathogenic Fusarium species of mango malformation namely $F$. subglutinans, $F$. sterilihyphosum, $F$. oxysporum and $F$. proliferatum. The Polymorphism of RAPD profiles have also been observed in various isolates of Fusarium species such as F. moniliforme, F. subglutinans, F. oxysporum and F. proliferatum $[13,14]$.

\section{ACKNOWLEDGEMENTS}

This manuscript funded from the project "New applied approaches to promote productivity and Quality of some fruit crops (Mango)" National Research Centre, 2007 to 2010. Also, this paper publish from Thesis under title of biological and molecular characterization for controlling mango malformation disease. PI: Dr. Wafaa Haggag.

\section{REFERENCES}

[1] Ploetz, R.C. (2001) Malformation: A unique and important disease of mango, Mangifera indica L. In: Summerell, B.A., Leslie, J.F., Backhouse, D. and Bryden, W. Eds., Fusarium: Paul E. Nelson Memorial Symposium, American Phytopathological Society (APS) Press, St Paul, 233-247.
[2] Kumar, J. and Beniwal, S.P. (1987) A method of estimating cultivar susceptibility against mango malformation. Tropical Pest Management, 33, 208-210. doi:10.1080/09670878709371151

[3] Lima, C.S., Pfenning, L.H., Costa, S.S., Campos, M.A. and Leslie, J.F. (2009) A new Fusarium lineage within the Gibberella fujikuroi species complex is the main causal agent of mango malformation disease in Brazil. Plant Pathology, 58, 33-42. doi:10.1111/j.1365-3059.2008.01946.x

[4] Zheng, Q. and Ploetz, R. (2002) Genetic diversity in, and development of a PCR assay for identifying, the mango malformation pathogen. Plant Pathology, 51, 208-216. doi:10.1046/j.1365-3059.2002.00677.x

[5] Freeman, S., Maimon, M. and Pinkas, Y. (1999) Use of GUS transformants of Fusarium subglutinans for determining etiology of mango malformation disease. Phytopathology, 89, 456-461. doi:10.1094/PHYTO.1999.89.6.456

[6] Youssef, S. A., Maymon, M., Zveibil, A., Klein-Gueta, D., Sztejnberg, A., Shalaby, A.A. and Freeman, S. (2007) Epidemiological aspects of mango malformation disease caused by Fusarium mangiferae and source of infection in seedlings cultivated in orchards in Egypt. Plant $\mathrm{Pa}$ thology, 56, 257-263. doi:10.1111/j.1365-3059.2006.01548.x

[7] Reuveni, R., Shimoni, M., Karchi, Z. and Kuc, J. (1992) Peroxidase activity as a biochemical marker for resistance of muskmelon on (Cucumis meb) to Pseudoperonospora cubensis. Phytopathology, 82, 749-753. doi:10.1094/Phyto-82-749

[8] Stegemann, H., Afify, A. and Hussein, K.R.F. (1985) Cultivar Identification of dates (Phoenix dactylifera) by protein patterns. 2nd International Symposium of Biochemical Approaches to Identification of Cultivars, Braunschweing, 1985, 44.

[9] Doyle, J.J. and Doyle, J.L. (1990) Isolation of DNA from fresh tissue. Focus, 12, 13-15.

[10] Williams, K., Kublik, A., Livak, K., Rafalski, J. and Tingey, V. (1990) Useful as genetic markers. Nucleic Acids Research, 18, 6531-6535. doi:10.1093/nar/18.22.6531

[11] Zaccaro, S., Alves C.L., Travensolo, F., Wickert, E. and Lemos, M. (2007) Use of molecular marker SCAR in the identification of Fusarium subglutinans, causal agent of mango malformation. Revista Brasileira de Fruticultura, 29. doi: 10.1590/S0100-29452007000300029

[12] Nur, A., Izzati, M.Z. and Salleh, B. (2009) Genetic variability amongst Fusarium spp. in the section liseola from bakanae-infected rice in Malaysia and indonesia by rapd analysis. Malaysian Applied Biology, 38, 71-79.

[13] Vakalounakis, D., Wang, Z, Fragkiadakis, G., Skaracis, G. and Li, D. (2004) Characterization of Fusarium oxysporum isolates obtained from cucumber in China by pathogenicity, VCG and RAPD. Plant Disease, 88, 645649. doi:10.1094/PDIS.2004.88.6.645

[14] Zheng, Q. and Ploetz, R. (2002) Genetic diversity in, and development of a PCR assay for identifying, the mango malformation pathogen. Plant Pathology, 51, 208-216. doi:10.1046/j.1365-3059.2002.00677.x 